\title{
Human Pathology
}

National Cancer Institute

\section{Source}

National Cancer Institute. Human Pathology. NCI Thesaurus. Code C19435.

Branch of medicine concerned with the cause, origin, and nature of human disease, including the changes occurring as a result of disease. (from EPA Terminology Reference System) 